\title{
EFFECT OF COAL ASH ON THE MORPHOLOGICAL, THERMAL AND MECHANICAL PROPERTIES OF POLY(METHYL METHACRYLATE)
}

\author{
MUHAMMAD ISHAQ ${ }^{l}$, KHALID SAEED ${ }^{1,2}$ MUHAMMAD SHAKIRULLAH ${ }^{1}$, IMTIAZ AHMAD ${ }^{l}$, \\ TAYYIBA REHMAN ${ }^{1}$
}

\begin{abstract}
${ }^{I}$ Institute of Chemical Sciences, University of Peshawar, Peshawar-25120, Khyber Pukhtoonkhwa, Pakistan.
${ }^{2}$ Department of Chemistry, University of Malakand, Chakdara, Dir (Lower), Khyber Pukhtoonkhwa Pakistan.
\end{abstract}

(Received: April 5, 2011 - Accepted: December 20,2011)

\begin{abstract}
Composite materials of Coal ash/ Poly(Methyl Methacrylate) (ash/PMMA) were prepared/synthesized and their properties were studied by scanning electron microscopy (SEM), polarized optical microscopy (POM), differential scanning calorimetry (DSC), thermogravimetric analyzer (TGA) and universal testing machine (UTM). The morphological study presented that the ash particles were well dispersed and embedded within the PMMA matrix. The DSC thermograms showed that the melting temperature $\left(\mathrm{T}_{\mathrm{m}}\right)$ of pure PMMA is about $166^{\circ} \mathrm{C}$ which was shifted towards lower temperature when ash were incorporated in the polymer matrix. The mechanical properties of the ash/PMMA composites were enhanced up to an optimum level (ash $3 \mathrm{wt} \%$ ) and then decreased at higher incorporation of large quantity of filler. The TGA thermograms indicated that the thermal stability of the ash/PMMA composite was enhance significantly than pure PMMA.
\end{abstract}

Key words: Coal ash, PMMA, SEM, TGA

\section{INTRODUCTION}

Polymer composites reinforced with fillers/reinforced materials have paid significant attention due to the unique physical, mechanical, thermal and electrical properties of the reinforced materials. Extensive research is going on the polymer/reinforcing composite materials, in which they incorporated various kinds of fillers like carbon fiber, graphite, carbon nanotubes, nanoclay, etc. into the polymer matrix. The various properties such as electrical, mechanical, and thermal stability of the polymer improved significantly by incorporation of small amount of reinforcing materials. Xiang et al. ${ }^{1}$ prepared $\mathrm{pH}$ responsive organic/inorganic nanocomposites hydrogel. They incorporated the fibrillar attapulgite into poly(2-hydroxyethyl methacrylate-co-poly(ethylene glycol) methyl ether methacrylate-co-methacrylic acid), in which attapulgite fibril act as the cross-linker. The nanocomposite hydrogel showed improved response rate and mechanical properties. Zhong et al. ${ }^{2}$ prepared exfoliated poly(styrene)/ organo-modified montmorillonite (MMT) nanocomposites through In situ free radical bulk polymerization, in which they dispersed a modified reactive organophilic MMT layered silicate in styrene monomer. It was found that the nanocomposites show higher decomposition temperature, dynamic modulus, stronger shear thinning behavior and a smaller die swell ratio than pure poly(styrene). Saeed and Park prepared multiwalled carbon nanotubes (MWNTs)/Nylon-6 nanocomposites by In Situ polymerization method and it was found that the incorporation of MWNTs enhanced the electrical, mechanical and thermal properties of the nylon- $6 .{ }^{3}$ In an other attempt Saeed et al. prepared poly(caprolactone) (PCL) nanofibers and they found that the mechanical and thermal stability of the PCL nanofibers were enhanced by the incorporation of MWNTs but the electrical properties were shown only in the case when MWNTs were adsorbed onto PCL nanofibers mat.4.

In our present study, we prepared PMMA and coal ash composite via solution casting technique. PMMA is a common transparent thermoplastic polymeric (amorphous structure). It belongs to the family of biocompatible nonbiodegradable materials. PMMA possess various attractive properties like light weight, high light transmittance, chemical resistance, colorlessness, resistance to weathering corrosion, and good insulating properties. It is also used as a substituting material for inorganic glass, due to its higher impact strength and undergoes ductile rather than brittle fracture. Although, PMMA has good properties but the glass transition temperature (relatively low) limits makes its applications in the optical-electronic industry as well as for materials like compact discs (CDs), optical glasses..$^{5-8}$ The coal ashes are the waste material obtained after coal burning and choose as a reinforcing material in the present work. The Ash/PMMA composites were prepared by solution casting technique. The Ash/ PMMA composite were analyzed for the various properties such as morphological, mechanical and thermal properties using SEM, universal testing machine, DSC and TGA analyses.

\section{EXPERIMENTAL}

\section{Materials}

High density PMMA (Average molecular weight 3,50000) and chloroform were purchased from Aldrich. The Cherat coal sample was kindly, supplied by PMDC (Pakistan Mineral Development Corporation).

\section{Preparation of ash}

The crushed coal was heated in muffler furnace at $750{ }^{\circ} \mathrm{C}$ until the whole carbon particles were disappeared. The obtained ash was then screened through a screener $(60 \mu \mathrm{m}$ mesh size $)$ and used as reinforcing materials.

\section{Preparation of PMMA polymer}

The known weight of PMMA was first dissolved in $20 \mathrm{~mL}$ chloroform and then added $1 \mathrm{wt} \%$ of ash in the polymer solution and stir for $2 \mathrm{~h}$ on magnetic stirrer. The ash/PMMA solution was then placed in petri dish and a thin film of ash/PMMA composite was obtained after the evaporation of the solvent at room temperature. The same procedure was adopted for 3, 5 and $7 \mathrm{wt} \% \mathrm{ash} /$ PMMA composites.

\section{Instrumentation}

The Scanning Electron Microscopy (SEM) micrographs of the gold-coated fractured surfaces (broken in the liquid nitrogen) of the ash/PMMA composites were analyzed using a JEOL, JSM_5910 Scanning Electron Microscope (SEM).

The DSC analyses were performed using a Diamond Series DSC (Perkin Elmer). DSC thermograms were obtained at heating rate of $10{ }^{\circ} \mathrm{C} / \mathrm{min}$, under a nitrogen atmosphere in order to diminish oxidation. The TGA thermograms of the composites were obtained in nitrogen atmosphere, at a heating rate of 20 ${ }^{\circ} \mathrm{C} /$ min between $25^{\circ} \mathrm{C}$ and $600{ }^{\circ} \mathrm{C}$, using a Diamond TG/DTA (Perkin Elmer).

The mechanical properties were carried out by universal testing machine (Model 100-500KN, Iestometric Inc. UK). The tests were carried out at room temperature with crosshead speed of $50 \mathrm{~mm} / \mathrm{min}$. The sample dimensions were 70.9 (gauge length), 27 (width), 0.1 (thickness) $\mathrm{mm}^{3}$.

\section{RESULTS AND DISCUSSION}

\section{Morphology of Ash/PMMA}

Figure 1 shows the SEM images of coal ash (screened through a screener having mish size $60 \mu \mathrm{m})$ and the ash $(5 \mathrm{wt} \%) / \mathrm{PMMA}$ composite. It can be observed from figure 1a that the size of coal ash particles had several micrometers, which is present in agglomerate form. The coal ash had irregularshape with relatively smooth surfaces. The fractured surface of ash (5 wt \%)/ PMMA composite, which was broken in liquid nitrogen is shown in Figure 1b. The SEM image showed that the ash particles were not only well embedded within the polymer but also dispersed well within the PMMA matrix rather than agglomerate form.

Thermal properties of Ash/PMMA Composite

DSC analysis is an important technique in order to study the effect of reinforcing materials on the crystallization temperature and melting temperature of polymer matrix. The coal ash/PMMA composite samples with different amount of ash were subjected to DSC analyses in order to study 
the effect of ash on the melting temperature $\left(T_{m}\right)$ (Table 1). The $T_{m}$ of pure PMMA is $166^{\circ} \mathrm{C}$, which was decreased slightly with the increment of the ash amount incorporated to the polymer matrix. Some of the research groups also reported that the $T_{m}$ of the polymer decreased when they incorporated the reinforcing materials in the polymer matrix. Bizarria et al. reported that the $\mathrm{T}$ of the Clay/Poly(ethylene terephthalate) (PET) nanocomposites is lower than pure poly(ethylene terephthalate). ${ }^{9}$ They suggested that the lower $T_{m}$ of Clay/PET nanocomposite might be due to the nanoscale interactions between the polymer and the clay surface. It might result less stable crystals when the polymer crystallized from melted state. Similar, works were also reported by Ou et al. ${ }^{10}$ and Burnside et al. ${ }^{11}$, in which they incorporated nanoparticles in PET. They also reported that the $T_{m}$ of the composite systems were decreased slightly.

Table 1. DSC melting temperature of pure PMMA and Ash/PMMA composites.

\begin{tabular}{|c|c|}
\hline Sample & Melting Temperature $\left({ }^{\circ} \mathrm{C}\right)$ \\
\hline PMMA & 166 \\
\hline $1 \%$ ash/PMMA & 145 \\
\hline $3 \%$ ash/PMMA & 141 \\
\hline $5 \%$ ash/PMMA & 135 \\
\hline
\end{tabular}
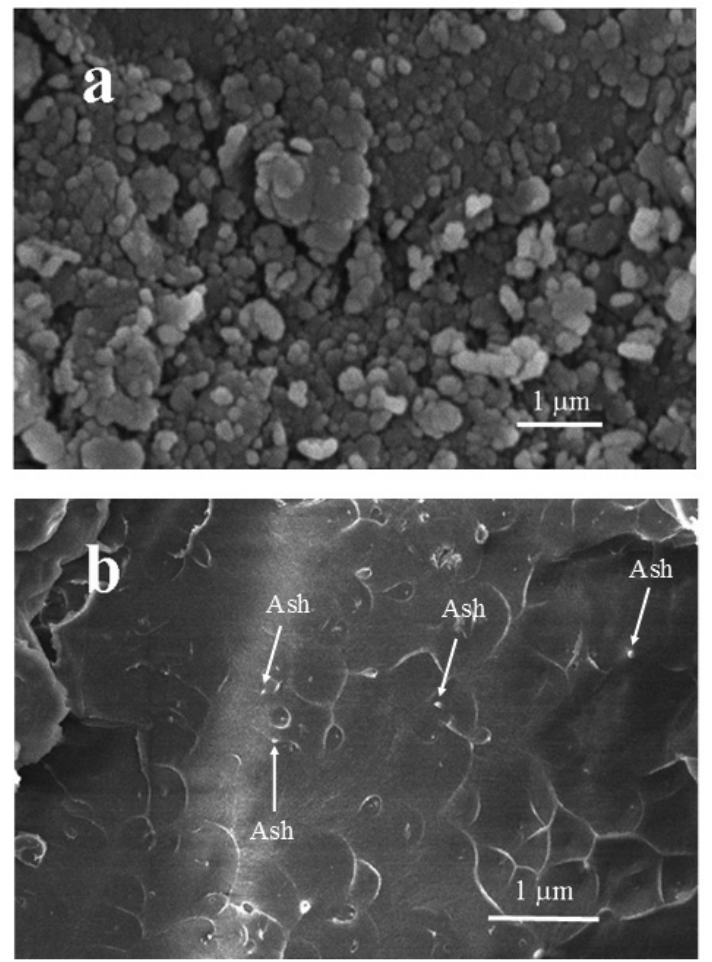

Figure 1. SEM images of the fractured surface (a) Ash and (b) Ash (5 wt $\%$ )/PMMA.

The TGA thermograms of pure PMMA and Ash (5 wt \%)/PMMA composite has been shown in figure 2. The TG curve presented that pure PMMA decomposed in three stages. The first stage of PMMA decomposition (about $150{ }^{\circ} \mathrm{C}$ ) is due to the loss of water and methyl methacrylate from the additive as well as residual acetone. The second stage decomposition begins at about $290{ }^{\circ} \mathrm{C}$, which might be due to the radical transfer to unsaturated chain ends. The weight loss with third stage (about $360{ }^{\circ} \mathrm{C}$ ) associated with random scission of the polymer backbone. ${ }^{12}$ The TGA thermogram of the Ash (5 wt \%)/ PMMA composite also presented three stage decomposition. The thermogram clearly indicated that the second and third stage of decomposition of the composite were shift to higher temperature as compared to pure PMMA. Both pure PMMA and Ash (5 wt \%)/PMMA composite decomposed completely at about $420{ }^{\circ} \mathrm{C}$. The residual amount, which was contributed by the coal ash in the composite, remained at higher temperatures. The TGA thermograms indicated that the incorporation of ash enhanced the thermal degradation of PMMA.

Table 2. Mechanical properties of Pure PMMA and Ash (5 wt \%)/PMMA.

\begin{tabular}{|c|c|c|c|}
\hline Sample & $\begin{array}{c}\text { Stress } \\
\left(\mathrm{N} / \mathrm{mm}^{2}\right)\end{array}$ & $\begin{array}{c}\text { Young's Modulus } \\
\left(\mathrm{N} / \mathrm{mm}^{2}\right)\end{array}$ & $\begin{array}{c}\text { Elongation at } \\
\text { break (\%) }\end{array}$ \\
\hline PMMA & 12.5 & 1185 & 1.4 \\
\hline $3 \%$ ash/PMMA & 63.0 & 4407 & 0.4 \\
\hline $5 \%$ ash/PMMA & 15.5 & 1450 & 0.9 \\
\hline
\end{tabular}

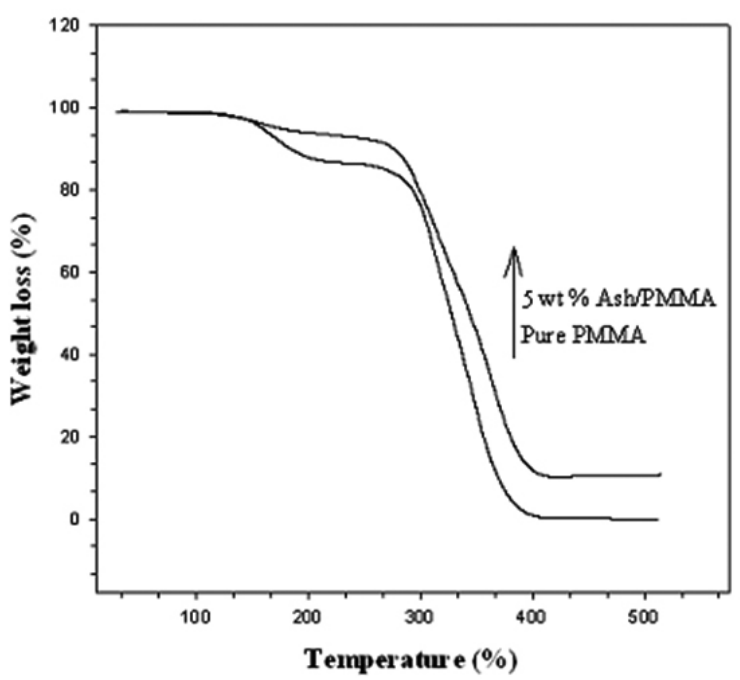

Figure 2. TGA thermograms of pure PMMA and Ash (5 wt \%)/PMMA composite.

\section{Mechanical properties of Ash/PMMA}

The mechanical properties of the polymeric materials are comparatively low, which might be enhanced by the incorporation of other reinforcing materials. In the majority cases it has been shown that the inorganic additives have much improved mechanical properties as compared to organic polymer. ${ }^{13}$ Table 2 presents the mechanical properties of the pure PMMA and Ash/PMMA composite. The stress of the pure PMMA and 3 and $7 \mathrm{wt}$ $\%$ Ash/PMMA composites were 12.6, 63.0 and $15.5 \mathrm{~N} / \mathrm{mm}^{2}$ respectively, and Young's modulus of them were $1885,4407,1450 \mathrm{~N} / \mathrm{mm}^{2}$ 'respectively. The increased in the stress and modulus might be due to better dispersion of coal ash in the PMMA matrix. The enhancement in mechanical properties were higher at low ash concentration ( $3 \mathrm{wt} \%$ ), which were decreased when $7 \mathrm{wt}$ $\%$ ash incorporated. The decrease in mechanical properties might be due to agglomeration of ash particles ( $7 \mathrm{wt} \%$ ) in the PMMA matrix. As shown in table 2, the elongation at break of pure PMMA, and 3 and $7 \mathrm{wt} \%$ Ash/PMMA composites were $1.4,0.4$ and $0.9 \%$, respectively. The decrease in elongation at break of Ash/PMMA composites implies that the incorporation of ash to the PMMA matrix allow to obtain stronger polymeric materials but less flexible. ${ }^{14}$

\section{CONCLUSION}

In summary, we have demonstrated that the Ash/PMMA composites showed higher mechanical properties than pure PMMA, which was decreased as increased the amount of ash (instead of dispersion agglomeration of ash particles) in the PMMA matrix. The $\mathrm{T}_{\mathrm{m}}$ of pure PMMA is $166{ }^{\circ} \mathrm{C}$, which was decreased by the incorporation of ash in the polymer matrix. It was also found that the thermal stability of Ash/PMMA composite was enhanced than that of pure PMMA.

\section{REFERENCES}

1. Y. Xiang, Z. Peng, D. Chen, Eur. Polym. J., 42, 2125, (2006).

2. Y. Zhong, Z. Zhu, S.-Q. Wang, Polymer, 46, 3006, (2005).

3. K. Saeed, S.-Y. Park, J. Appl. Polym. Sci., 106, 3729, (2007).

4. K. Saeed, S.-Y. Park, M. Ishaq, J. Chil. Chem. Soc., 54, 289-292, (2009). 
5. K. Yuichi, J. Appl. Polym. Sci., 63, 363, (1997).

6. T. Otsu, T. Motsumoto, Polym. Bull., 23, 43, (1990).

7. M.M. Demir, M. Memesa, P. Castignolles, G. Wegner, Macromol. Rapid Commun., 27, 763-770, (2006).

8. M. Babazadeh, J. Appl. Polym. Sci., 102, 4989, (2006).

9. M.T.M. Bizarria, A.L.F. de M. Giraldi, C.M. de Carvalho, J. I. Velasco, M.A. d'A' vila, L. H. I. Mei. J. Appl. Polym. Sci., 104, 1839, (2007).
10. C.F. Ou, M.T. Ho, J. R. Lin, J. Polym. Res., 10, 127, (2003).

11. S.D. Burnside, E.P. Giannelis, Chem Mater., 7, 1597 (1995).

12. E. Kandare, H. Deng, D. Wang, J. M. Hossenlopp, Polym. Adv. Technol., 17, 312, (2006).

13. F. Yang, G.L. Nelson, J. Appl. Polym. Sci., 91, 3844, (2004).

14. J. Gao, M.E. Itkis, A. Yu, E. Bekyarova, B. Zhao, R.C. Haddon, J. Am. Chem. Soc. 127, 3847, (2005). 